\title{
Superiority of lymph node ratio-based staging system for prognostic prediction in 2575 patients with gastric cancer: validation analysis in a large single center
}

\author{
Lin-Yong Zhao ${ }^{1,2, *}$, Chang-Chun $\mathrm{Li}^{1,2, *}$ Lu-Yu Jia ${ }^{3}$, Xiao-Long Chen ${ }^{1,2}$, Wei-Han \\ Zhang $^{1,2}$, Xin-Zu Chen ${ }^{1,2}$, Kun Yang ${ }^{1,2}$, Kai Liu' ${ }^{1,2}$, Yi-Gao Wang ${ }^{1,2}$, Lian-Xue ${ }^{1,2}$ Bo \\ Zhang $^{1}$, Zhi-Xin Chen ${ }^{1}$, Jia-Ping Chen ${ }^{1}$, Zong-Guang Zhou ${ }^{1}$, Jian-Kun Hu ${ }^{1,2}$ \\ ${ }^{1}$ Department of Gastrointestinal Surgery, West China Hospital, Sichuan University, Chengdu, Sichuan, China \\ ${ }^{2}$ Laboratory of Gastric Cancer, State Key Laboratory of Biotherapy/Collaborative Innovation Center of Biotherapy, West China \\ Hospital, Sichuan University, Chengdu, Sichuan, China \\ ${ }^{3}$ West China School of Pharmacy, Sichuan University, Chengdu, Sichuan, China \\ *These authors contributed equally to this work
}

Correspondence to: Jian-Kun Hu, email: hujkwch@126.com

Keywords: gastric cancer, lymph node ratio, staging, prediction

Received: March 19, 2016 Accepted: May 17, $2016 \quad$ Published: May 30, 2016

\section{ABSTRACT}

This study aimed to evaluate the prognostic significance of node ratio ( $\mathrm{Nr}$ ), the ratio of metastatic to retrieved lymph nodes, and to investigate whether a modified staging system based on $\mathrm{Nr}$ can improve prognostic ability for gastric cancer patients following gastrectomy. A total of $\mathbf{2 5 7 2}$ patients were randomly divided into training set and validation set, and the cutoff points for $\mathrm{Nr}$ were produced using $\mathrm{X}$-tile. The relationships between $\mathrm{Nr}$ and other clinicopathologic factors were analyzed, while survival prognostic discriminatory ability and accuracy were compared among different staging systems by AIC and C-index in R program. Patients were categorized into four groups as follows: Nr0, Nr1: 0.00-0.15, Nr2: 0.15-0.40 and Nr3: $>0.40$. $\mathrm{Nr}$ was significantly associated with clinicopathologic factors including macroscopic type, tumor differentiation, lymphovascular invasion, perineural invasion, tumor size, $\mathrm{T}$ stage, $\mathrm{N}$ stage and TNM stage. Besides, for all patients, $\mathrm{Nr}$ and TNrM staging system showed a smaller AIC and a larger $\mathbf{C}$-index than that of $\mathbf{N}$ and TNM staging system, respectively. Moreover, in subgroup analysis for patients with retrieved lymph nodes $<15$, $\mathrm{Nr}$ was demonstrated to have a smaller AIC and a larger C-index than $\mathbf{N}$ staging system. Furthermore, in validation analysis, $\mathrm{Nr}$, categorized by our cutoff points, showed a larger C-index and a smaller AIC value than those produced in previous studies. Nr could be considered as a reliable prognostic factor, even in patients with insufficient $(<15)$ retrieved lymph nodes, and TNrM staging system may improve the prognostic discriminatory ability and accuracy for gastric cancer patients undergoing radical gastrectomy.

\section{INTRODUCTION}

As one of the most common malignances, gastric cancer (GC)is nowadays the secondary leading cause of cancer-related mortality in China, in spite of a declining global incidence [1]. The identification of its prognostic factors becomes of great importance for the survival prediction of gastric cancer patients. Currently, tumornode-metastasis (TNM) staging system, as the most commonly used staging system for gastric cancer, is applied both in the Japanese Gastric Cancer Association (JGCA) [2] and the American Joint Committee on Cancer (AJCC) [3], not only because of its discriminatory power on the prognostic difference but also due to its predictive accuracy. However, it requires examining at least 15 lymph nodes to make $\mathrm{N}$ staging adequately and accurately, which has limited its use in clinical practice. Fortunately, node ratio $(\mathrm{Nr})$, defined as the ratio of the positive 
lymph nodes to the retrieved lymph nodes, needless of considering the number of retrieved lymph nodes, which was regarded as an alternative system to $\mathrm{N}$ staging system, has been identified as an important independent prognostic factor in majority of studies [4-12]. Nevertheless, these findings are not universally supported [13, 14], and $\mathrm{Nr}$ has not yet been integrated into the current staging system for gastric cancer up till now. Thus, the controversy for the prognostic significance of $\mathrm{Nr}$ still remains.

In light of these considerations mentioned above, we performed this study to evaluate the prognostic significance of node ratio $(\mathrm{Nr})$, and to investigate whether a modified staging system, TNrM which is based on $\mathrm{Nr}$, can improve prognostic discriminatory ability and predictive accuracy for gastric cancer patients undergoing gastrectomy.

\section{RESULT}

\section{Correlation analysis between the clinicopathologic factors and node ratio}

X-tile plots, constructed in Figure 1, illustrated that the optimal cutoff points for node ratio $(\mathrm{Nr})$ were 0.15 and 0.40 in node-positive patients using minimum $P$ value from log-rank $\chi^{2}$ test, according to which patients were categorized into four groups, $\mathrm{Nr} 0: 0.0 \mathrm{Nr}$ 1:0.0$0.15, \mathrm{Nr} 2: 0.15-0.40, \mathrm{Nr} 3:>0.40$, with the strongest discriminatory capacity.

Clinicopathologic factors were compared between the training set and validation set, and among the four groups, as shown in Table 1. There was no significant difference between the training set and validation set regarding all the clinicopathologic factors (all the $p^{*}$ value $>0.05$ ), which meant that the baseline was balanced

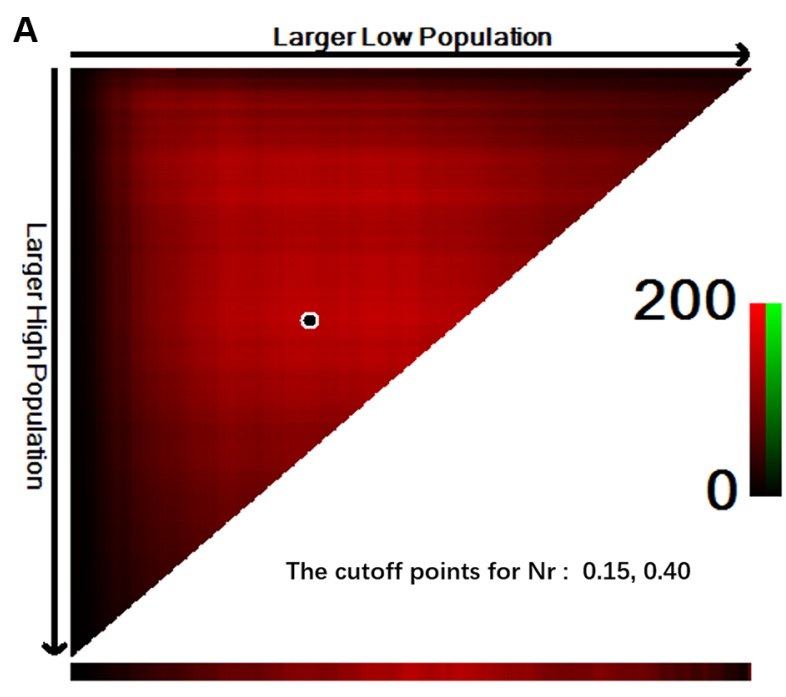

between them. Besides, both in the training and validation set, $\mathrm{Nr}$ stage was found to be significantly associated with macroscopic type, tumor differentiation, lymphovascular invasion, perineural invasion, tumor size, $\mathrm{T}$ stage, $\mathrm{N}$ stage and TNM stage (all the $p$ value $<0.05$ ). However, no significance was found between $\mathrm{Nr}$ and age, gender as well as adjuvant chemotherapy. There were significantly more patients with macroscopic type III-IV, poorly tumor differentiation, positive lymphovascular/perineural invasion, larger tumor size and advanced TNM stage in higher node ratio stages $(\mathrm{Nr} 2$ and $\mathrm{Nr} 3)$ than that in lower node ratio stages $(\mathrm{Nr} 0$ and $\mathrm{Nr} 1)$.

\section{Identification of risk factors and multicollinearit analysis for node ratio}

As illustrated in Table 2, logistic regression analysis was performed to determine the risk factors for Nr. In the univariate analysis, the involved factors significantly consisted of clinicopathologic factors, such as age $(\mathrm{OR}=1.165, p=0.022)$, tumor location (OR $=0.382, p=0.003)$, macroscopic type $(\mathrm{OR}=1.430$, $p<0.001)$, tumor differentiation $(\mathrm{OR}=1.697$, $p<0.001)$, lymphovascular invasion $(\mathrm{OR}=1.436, p=0.023)$, perineural invasion $(\mathrm{OR}=1.037, \mathrm{p}=0.052)$, tumor size $(\mathrm{OR}=1.541, p=0.011)$, $\mathrm{T}$ stage $(\mathrm{OR}=1.234$, $p=0.023)$ and $\mathrm{N}$ stage $(\mathrm{OR}=3.812, p<0.001)$. Multivariate logistic regression model analysis indicated that tumor differentiation $(\mathrm{OR}=1.045, p=0.010)$, lymphovascular invasion (OR $=1.011, p=0.045)$ and $\mathrm{N}$ stage $(\mathrm{OR}=2.631, p<0.001)$ were independent risk factors for $\mathrm{Nr}$.

In order to assess the multicollinearity between $\mathrm{Nr}$ and these independent factors identified above, spearman correlation analyses were performed in Table 3,

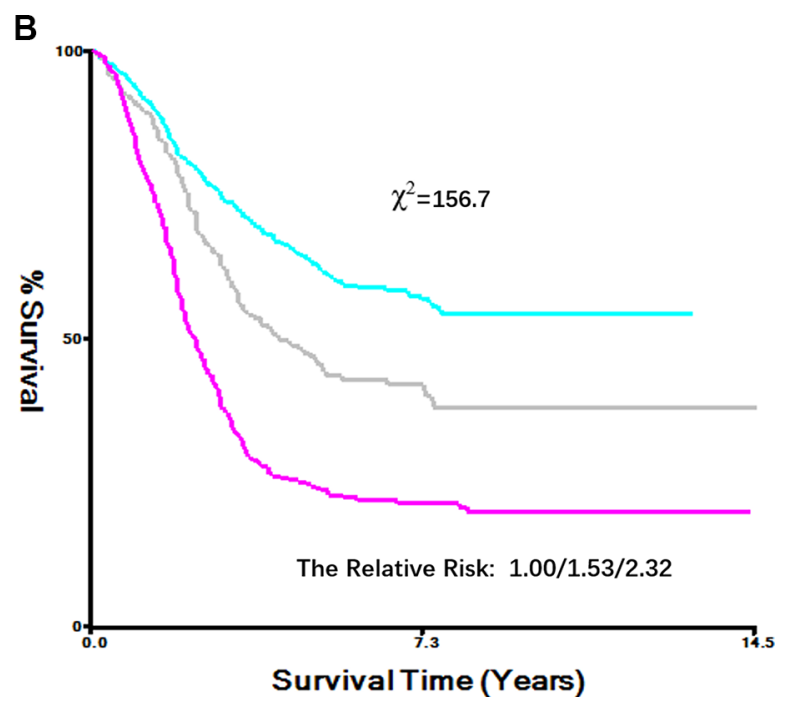

Figure 1: Division of patients by the cutoff points produced by X-tile plot. (A) X-tile plots for lymph node ratio (Nr). The plots illustrate that the produced log-rank $\chi^{2}$ value stratify the node-positive patients into 3 groups by two cutoff points, 0.15 and 0.40 . (B), survival curves generated by X-tile plots, show a strong discriminatory capacity, with a $\chi^{2}$ value of 156.7 and a relative risk ratio of $1.00 / 1.53 / 2.32$. 
Table 1: Patients and clinicopathologic factors

\begin{tabular}{|c|c|c|c|c|c|c|c|c|c|c|c|c|c|}
\hline \multirow[b]{2}{*}{ Factors } & \multicolumn{6}{|c|}{ Training set } & \multicolumn{6}{|c|}{ Validation set } & \multirow[t]{2}{*}{$\mathbf{P}^{*}$} \\
\hline & $\begin{array}{l}\text { Nr0 } \\
(n= \\
701)\end{array}$ & $\begin{array}{c}\text { Nr1 } \\
(n=441)\end{array}$ & $\begin{array}{l}\text { Nr2 } \\
(n= \\
484)\end{array}$ & $\begin{array}{c}\text { Nr3 } \\
(n=477)\end{array}$ & $\begin{array}{c}\text { Total } \\
(n= \\
2103)\end{array}$ & $P$ & $\begin{array}{l}\text { Nr0 } \\
(n= \\
157)\end{array}$ & $\begin{array}{c}\text { Nr1 } \\
(n=115)\end{array}$ & $\begin{array}{l}\text { Nr2 } \\
(n= \\
109)\end{array}$ & $\begin{array}{c}\text { Nr3 } \\
(n=91)\end{array}$ & $\begin{array}{c}\text { Total } \\
(n=472)\end{array}$ & $P$ & \\
\hline Gender & & & & & & 0.172 & & & & & & 0.248 & 0.051 \\
\hline Male & 501 & 308 & 361 & 333 & 1503 & & 103 & 75 & 71 & 67 & 316 & & \\
\hline Female & 200 & 133 & 123 & 144 & 600 & & 54 & 40 & 38 & 24 & 156 & & \\
\hline Age (years) & & & & & & 0.067 & & & & & & 0.131 & 0.059 \\
\hline$\geq 60$ & 308 & 213 & 209 & 194 & 924 & & 73 & 57 & 48 & 52 & 230 & & \\
\hline$<60$ & 393 & 228 & 272 & 286 & 1179 & & 84 & 58 & 61 & 39 & 242 & & \\
\hline Tumor location & & & & & & 0.152 & & & & & & 0.245 & 0.112 \\
\hline Upper third & 175 & 104 & 128 & 117 & 524 & & 39 & 20 & 25 & 19 & 103 & & \\
\hline Middle third & 155 & 96 & 96 & 119 & 466 & & 38 & 39 & 29 & 22 & 128 & & \\
\hline Lower third & 357 & 232 & 253 & 230 & 1072 & & 77 & 55 & 53 & 46 & 231 & & \\
\hline$\geq 2 / 3$ stomach & 14 & 9 & 7 & 11 & 41 & & 3 & 1 & 2 & 4 & 10 & & \\
\hline Macroscopic type & & & & & & $<0.001$ & & & & & & $<0.001$ & 0.069 \\
\hline Borrmann 0-II & 395 & 284 & 280 & 225 & 1184 & & 85 & 83 & 59 & 17 & 244 & & \\
\hline $\begin{array}{l}\text { Borrmann III- } \\
\text { IV }\end{array}$ & 306 & 157 & 204 & 252 & 919 & & 72 & 32 & 50 & 74 & 228 & & \\
\hline $\begin{array}{l}\text { Tumor } \\
\text { differentiation }\end{array}$ & & & & & & $<0.001$ & & & & & & $<0.001$ & 0.141 \\
\hline $\begin{array}{c}\text { Well/ } \\
\text { Moderately }\end{array}$ & 138 & 124 & 96 & 56 & 414 & & 30 & 25 & 16 & 8 & 79 & & \\
\hline Poorly & 563 & 317 & 388 & 421 & 1689 & & 127 & 90 & 93 & 83 & 393 & & \\
\hline $\begin{array}{l}\text { Lymphovascular } \\
\text { invasion }\end{array}$ & & & & & & 0.008 & & & & & & 0.003 & 0.083 \\
\hline Negative & 437 & 292 & 305 & 275 & 1311 & & 90 & 82 & 60 & 42 & 274 & & \\
\hline Positive & 264 & 147 & 179 & 202 & 792 & & 67 & 33 & 49 & 49 & 198 & & \\
\hline $\begin{array}{l}\text { Perineural } \\
\text { invasion }\end{array}$ & & & & & & 0.004 & & & & & & $<0.001$ & 0.054 \\
\hline Negative & 560 & 374 & 377 & 368 & 1679 & & 121 & 91 & 69 & 67 & 358 & & \\
\hline Positive & 141 & 67 & 107 & 109 & 424 & & 36 & 14 & 40 & 24 & 114 & & \\
\hline $\begin{array}{l}\text { Adjuvant } \\
\text { chemotherapy }\end{array}$ & & & & & & 0.087 & & & & & & 0.271 & 0.090 \\
\hline Present & 254 & 181 & 195 & 207 & 837 & & 47 & 45 & 44 & 32 & 168 & & \\
\hline Absent/Unclear & 447 & 260 & 299 & 270 & 1266 & & 110 & 70 & 65 & 59 & 304 & & \\
\hline Tumor size & & & & & & $<0.001$ & & & & & & $<0.001$ & 0.102 \\
\hline$\leq 4.5 \mathrm{~cm}$ & 234 & 191 & 178 & 99 & 702 & & 51 & 54 & 49 & 17 & 171 & & \\
\hline $4.5-7.5 \mathrm{~cm}$ & 330 & 188 & 230 & 241 & 989 & & 71 & 49 & 43 & 33 & 196 & & \\
\hline$\geq 7.5 \mathrm{~cm}$ & 137 & 62 & 73 & 140 & 412 & & 35 & 12 & 17 & 41 & 105 & & \\
\hline $\begin{array}{l}\text { Retrieved lymph } \\
\text { nodes }\end{array}$ & & & & & & 0.901 & & & & & & 0.900 & 0.121 \\
\hline$\geq 15$ & 499 & 323 & 348 & 342 & 1512 & & 119 & 87 & 84 & 66 & 356 & & \\
\hline$<15$ & 202 & 118 & 136 & 135 & 591 & & 38 & 28 & 25 & 25 & 116 & & \\
\hline T Stage & & & & & & $<0.001$ & & & & & & \begin{tabular}{|c|}
$<0.001$ \\
\end{tabular} & 0.097 \\
\hline $\mathrm{T} 1$ & 42 & 52 & 27 & 6 & 127 & & 13 & 17 & 3 & 6 & 39 & & \\
\hline $\mathrm{T} 2$ & 81 & 74 & 60 & 28 & 243 & & 22 & 29 & 13 & 2 & 66 & & \\
\hline $\mathrm{T} 3$ & 57 & 54 & 41 & 19 & 171 & & 10 & 7 & 7 & 6 & 30 & & \\
\hline $\mathrm{T} 4 \mathrm{a}$ & 435 & 229 & 309 & 331 & 1304 & & 91 & 57 & 79 & 63 & 290 & & \\
\hline $\mathrm{T} 4 \mathrm{~b}$ & 86 & 32 & 47 & 93 & 258 & & 21 & 5 & 7 & 14 & 47 & & \\
\hline N Stage & & & & & & $<0.001$ & & & & & & $<0.001$ & 0.194 \\
\hline No & 701 & 0 & 0 & 0 & 701 & & 157 & 0 & 0 & 0 & 157 & & \\
\hline $\mathrm{N} 1$ & 0 & 316 & 68 & 21 & 405 & & 0 & 75 & 16 & 15 & 106 & & \\
\hline $\mathrm{N} 2$ & 0 & 119 & 216 & 84 & 419 & & 0 & 26 & 46 & 3 & 75 & & \\
\hline
\end{tabular}




\begin{tabular}{|c|c|c|c|c|c|c|c|c|c|c|c|c|c|}
\hline N3a & 0 & 6 & 184 & 215 & 405 & & 0 & 11 & 43 & 35 & 89 & & \\
\hline $\mathrm{N} 3 \mathrm{~b}$ & 0 & 0 & 16 & 157 & 173 & & 0 & 3 & 4 & 38 & 45 & & \\
\hline TNM Stage & & & & & & $<0.001$ & & & & & & $<0.001$ & 0.066 \\
\hline IA & 290 & 0 & 0 & 0 & 290 & & 51 & 0 & 0 & 0 & 51 & & \\
\hline IB & 129 & 50 & 11 & 2 & 192 & & 35 & 10 & 7 & 2 & 54 & & \\
\hline IIA & 101 & 64 & 22 & 3 & 190 & & 25 & 10 & 3 & 2 & 40 & & \\
\hline IIB & 92 & 47 & 36 & 12 & 187 & & 25 & 9 & 8 & 4 & 46 & & \\
\hline IIIA & 82 & 171 & 79 & 37 & 369 & & 20 & 66 & 6 & 11 & 103 & & \\
\hline IIIB & 7 & 92 & 167 & 75 & 341 & & 1 & 17 & 48 & 12 & 78 & & \\
\hline IIIC & 0 & 17 & 169 & 348 & 534 & & 0 & 3 & 37 & 60 & 100 & & \\
\hline
\end{tabular}

$P^{*}$ : the difference between the training set and the validation set.

demonstrating that $\mathrm{N}$ stage was correlated with $\mathrm{Nr}(r=0.724$, $p<0.001$ ), while tumor differentiation, lymphovascular invasion and $\mathrm{T}$ stage showed no correlation with $\mathrm{Nr}$ (all the $r$ value $<0.3$ ). Additionally, scatter spots in Figure 2, suggested that there was positive linear correlation between the number of positive lymph node and $\mathrm{Nr}\left(R^{2}=0.457\right)$.

\section{Univariate and multivariate analyses of factors associated with patients' prognosis}

As shown in Table 4, the 5-year overall survival rates (5-y OS) for these four $\mathrm{Nr}$ stages were $72.5 \%$, $63.4 \%, 46.9 \%$ and $22.6 \%$, respectively, whereas the 5 -y OS for different TNrM stages were $82.5 \%, 80.8 \%$, $73.4 \%, 61.8 \%, 57.0 \%, 41.3 \%$ and $22.4 \%$, respectively. Univariate analysis with cox regression model in Table 5 showed clinicopathologic factors, including gender, age, macroscopic type, tumor differentiation, lymphovascular invasion, perineural invasion, adjuvant chemotherapy, tumor size, T stage and $\mathrm{N}$ stage as well as $\mathrm{Nr}$ stage, were significant prognostic factors for patients. However, multivariate analysis indicated that only age $(\mathrm{HR}=0.751$, $p<0.001)$, tumor size $(\mathrm{HR}=1.181, p=0.006)$, T stage $(\mathrm{HR}=1.271, p<0.001), \mathrm{N}$ stage $(\mathrm{HR}=1.209, p=0.003)$ and $\mathrm{Nr}$ stage $(\mathrm{HR}=1.413, p<0.001)$ were independent prognostic factors for gastric cancer patients, after adjustment of the confounding factors.

\section{Comparison and validation of different staging systems}

Akaike information criterion (AIC) and concordance index (C-index) values for each staging system in Table 4 were calculated to evaluate the prognostic discriminatory ability and predictive accuracy, respectively. Compared with $\mathrm{N}$ staging system, $\mathrm{Nr}$ staging system had a smaller $\mathrm{AIC}$ value and a larger $\mathrm{C}$-index $(p<0.05$, Figure $3 \mathrm{~A}$ and $3 \mathrm{~B}$ ), indicating that $\mathrm{Nr}$ stage was advantageous to $\mathrm{N}$ stage in survival prediction discriminatory ability and accuracy. In addition, TNrM staging system was found to be with a larger C-index and a smaller AIC than that of current TNM staging system $(p<0.05)$, and overlapping curves were found in the TNM staging system but not in the TNrM staging system (Figure 3C and 3D), with no significant difference on survival between stage IA and IB $(p=0.340)$, stage IB and stage IIA $(p=0.116)$, stage IIA and IIB ( $p=0.080)$ existing in the current TNM staging system, which illustrated that TNrM staging system had a better discriminatory ability and accuracy than that of TNM staging system in prognostic prediction. In the subgroup analysis, for patients with retrieved lymph nodes $<15$, $\mathrm{Nr}$ staging system $($ AIC $=883.2$; $\mathrm{C}$-index $=0.683)$ suggested significant improvement than $\mathrm{N}$ staging system $(\mathrm{AIC}=889.7 ; \mathrm{C}$-index $=0.603)$ $(p<0.05$, Figure 4A and 4B), whereas no significant difference was found between $\mathrm{Nr}$ and $\mathrm{N}$ staging system in patients with retrieved lymph nodes $\geq 15$ in prognostic discriminatory ability and predictive accuracy $(p>0.05$, Figure 4C and 4D).

We also respectively applied the $\mathrm{Nr}$ and $\mathrm{TNrM}$ staging system in the validation set, found that the results were as same as that in the training set: both of $\mathrm{Nr}$ and TNrM staging revealed significant superiority to their counterparts, $\mathrm{N}$ and TNM staging system. Furthermore, nomograms were used to predict 5-year OS of patients. Both in the training set and validation set, $\mathrm{Nr}$ was selected as an independent prognostic factor in nomograms (Figure 5A and 5C), which was similar to those of aforementioned multivariate analysis by cox regression. Moreover, corresponding calibration curves in the two sets suggested that the predictive probability of 5 -year survival were closely to the actual 5-year survival t (Figure 5B and 5D).

In order to evaluate how much improvement was gained using the cutoff points in this study, we also validated the different cutoff points reported in previous studies to create several predictive staging systems, generating various $\mathrm{AIC}$ values and $\mathrm{C}$-indexes, as shown in Table 6. We furtherly compared them to the AIC and $\mathrm{C}$-index produced in our study, and found that the cutoff points, $0,0.15,0.40$, in our study, had a larger $\mathrm{C}$-index and a smaller AIC value than those produced in previous studies (all $p<0.05$, Table 6), illustrating the cutoff points produced in our study using X-tile were the optimal ones. 
Table 2: Logistic regression analysis of the risk factors for node ratio ( $\mathrm{Nr}$ )

\begin{tabular}{|l|c|c|c|c|}
\hline \multicolumn{1}{c}{ Factors } & \multicolumn{2}{c}{ Univariate analysis } & \multicolumn{2}{c}{ Multivariate analysis } \\
\cline { 2 - 5 } \multicolumn{1}{c|}{ OR $(\mathbf{9 5 \%}$ CI) } & $1.004(0.758-1.332)$ & 0.187 & - & - \\
\hline Gender & $1.165(1.022-1.328)$ & 0.022 & $0.856(0.640-1.146)$ & 0.244 \\
\hline Age & $0.382(0.202-0.723)$ & 0.003 & $1.020(0.861-1.208)$ & 0.973 \\
\hline Tumor location & $1.430(1.252-1.633)$ & $<0.001$ & $0.807(0.602-1.082)$ & 0.277 \\
\hline Macroscopic type & $1.697(1.433-2.010)$ & $<0.001$ & $1.045(1.008-1.321)$ & 0.010 \\
\hline Tumor differentiation & $1.436(1.115-1.798)$ & 0.023 & $1.011(1.002-1.230)$ & 0.045 \\
\hline Lymphovascular invasion & $1.037(0.931-1.041)$ & 0.052 & - & - \\
\hline Perineural invasion & $0.843(0.665-1.210)$ & 0.310 & - & - \\
\hline Adjuvant chemotherapy & $1.541(1.326-1.791)$ & 0.011 & $0.903(0.667-1.221)$ & 0.507 \\
\hline Tumor size & $0.923(0.771-1.132)$ & 0.123 & - & - \\
\hline Retrieved lymph node & $1.234(1.012-1.991)$ & 0.023 & $1.085(0.910-1.236)$ & 0.064 \\
\hline T Stage & $3.812(2.467-4.943)$ & $<0.001$ & $2.631(1.912-3.676)$ & $<0.001$ \\
\hline N Stage & & & - & - \\
\hline
\end{tabular}

OR: Odds Ratio; CI: Confidence Interval.

Table 3: Spearman correlation analysis of the multicollinearity for node ratio (Nr)

\begin{tabular}{|l|c|c|}
\hline \multicolumn{1}{|c|}{ Factors } & Correlation coefficient (r) & $<$ value \\
\hline Tumor differentiation & $0.166^{*}$ & $<0.001$ \\
\hline Lymphovascular invasion & $0.214^{*}$ & $<0.001$ \\
\hline T Stage & $0.290^{*}$ & $<0.001$ \\
\hline N Stage & $0.724^{*}$ & $<0.001$ \\
\hline
\end{tabular}

*Correlation is significant at the 0.01 level (2 tailed);

r: correlation coefficient; $|\mathrm{r}|<0.3$ : no correlation; $0.3 \geq|\mathrm{r}|$ : correlation exists.

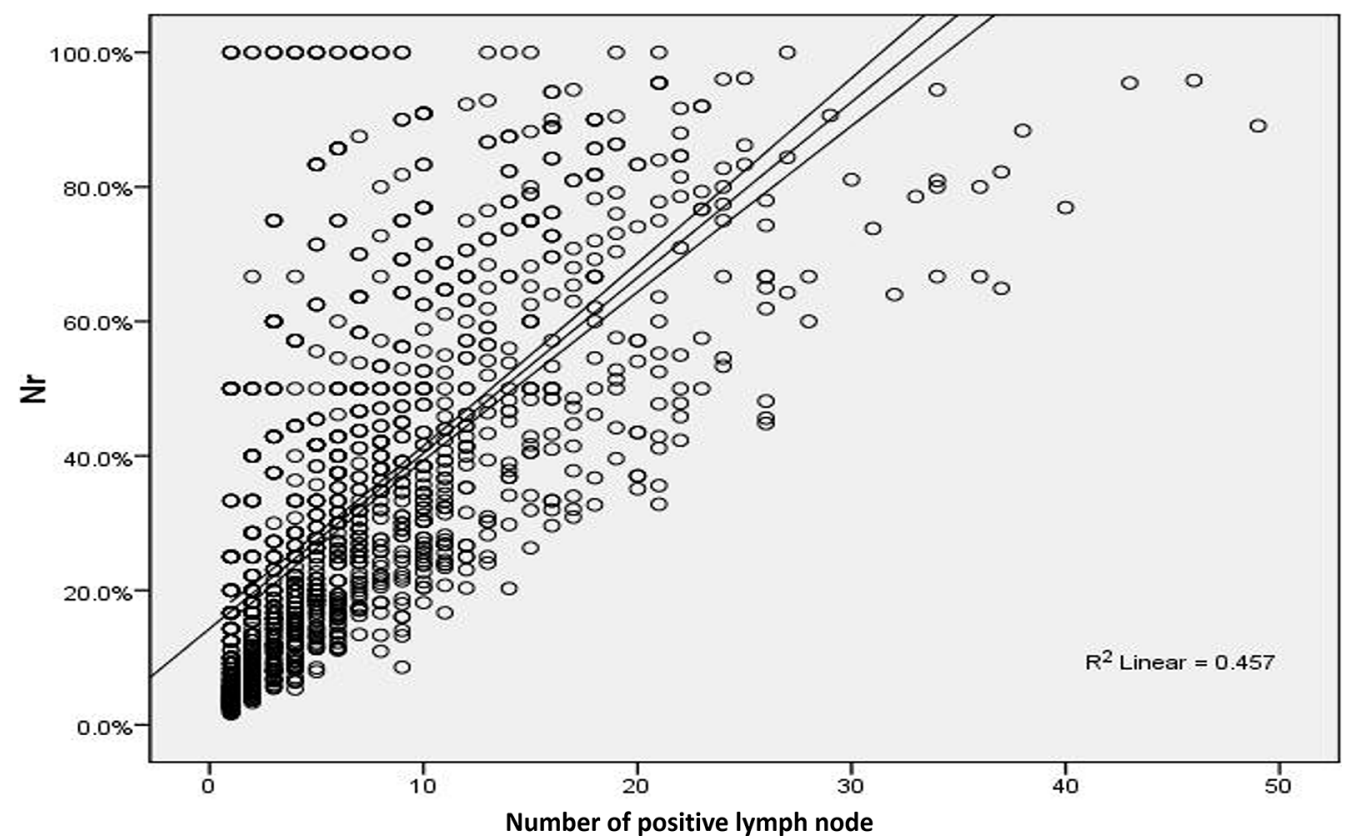

Figure 2: Positive linear correlation between the number of positive lymph node and $\mathrm{Nr}\left(\mathrm{R}^{2}=0.457\right)$ in scatter spots. 
Table 4: Prognostic prediction by Kapplan-Meier survival analyses

\begin{tabular}{|c|c|c|c|c|c|c|c|}
\hline Factors & $\begin{array}{c}\text { 3-year OS } \\
(\%)\end{array}$ & $\begin{array}{c}\text { 5-year OS } \\
(\%)\end{array}$ & MS (months) & AIC & C-index & $\begin{array}{c}\text { Log rank } \chi^{2} \\
\text { value }\end{array}$ & $P$ \\
\hline N stage & & & & 898.7 & 0.687 & 151.1 & $<0.001$ \\
\hline N0 & 85.2 & 72.5 & $124.1(7.5-176.0)$ & & & & \\
\hline $\mathrm{N} 1$ & 76.1 & 63.4 & $113.0(3.5-174.0)$ & & & & \\
\hline $\mathrm{N} 2$ & 67.1 & 52.8 & $99.5(1.4-172.4)$ & & & & \\
\hline N3a & 42.3 & 27.5 & $29.9(0.9-160.0)$ & & & & \\
\hline $\mathrm{N} 3 \mathrm{~b}$ & 26.5 & 20.4 & $23.0(0.3-172.7)$ & & & & \\
\hline $\mathrm{Nr}$ stage & & & & 880.1 & 0.696 & 156.7 & $<0.001$ \\
\hline $\mathrm{Nr} 0$ & 85.2 & 72.5 & $124.1(7.5-176.0)$ & & & & \\
\hline $\mathrm{Nr} 1$ & 78.3 & 63.4 & $106.0(1.4-160.0)$ & & & & \\
\hline $\mathrm{Nr} 2$ & 58.4 & 46.9 & $54.9(0.3-174.0)$ & & & & \\
\hline $\mathrm{Nr} 3$ & 30.4 & 22.6 & $26.1(0.9-172.7)$ & & & & \\
\hline TNM stage & & & & 872.3 & 0.754 & 161.7 & $<0.001$ \\
\hline IA & 92.6 & 82.5 & $134.2(9.3-156.2)$ & & & & \\
\hline IB & 87.3 & 77.2 & $121.2(1.4-172.4)$ & & & & \\
\hline IIA & 81.1 & 71.6 & $101.3(0.3-174.0)$ & & & & \\
\hline IIB & 79.8 & 60.6 & $92.7(4.0-176.0)$ & & & & \\
\hline IIIA & 66,2 & 55.4 & $82.6(5.4-157.2)$ & & & & \\
\hline IIIB & 55.9 & 46.2 & $46.6(0.9-150.3)$ & & & & \\
\hline IIIC & 33.1 & 22.2 & $25.4(0.8-172.7)$ & & & & \\
\hline TNrM stage & & & & 850.4 & 0.799 & 182.3 & $<0.001$ \\
\hline IA & 92.6 & 82.5 & $134.2(9.3-165.2)$ & & & & \\
\hline IB & 90.4 & 80.8 & $112.5(6.5-176.0)$ & & & & \\
\hline IIA & 85.0 & 73.4 & $98.4(1.4-160.9)$ & & & & \\
\hline IIB & 79.5 & 61.8 & $84.6(0.3-173.1)$ & & & & \\
\hline IIIA & 64.3 & 57.0 & $65.4(0.8-161.8)$ & & & & \\
\hline IIIB & 56.4 & 41.3 & $47.3(0.9-175.6)$ & & & & \\
\hline IIIC & 30.2 & 22.4 & $24.0(0.6-172.3)$ & & & & \\
\hline
\end{tabular}

OS: overall survival ; MS: median survival time; AIC: Akaike Information Criterion value; C-index: concordance index.

\section{DISCUSSION}

Although a great many studies, evaluating the prognostic significance of $\mathrm{Nr}$ in patients with gastric cancer, illustrated that $\mathrm{Nr}$ was an independent predictor and more emphases should be put on it, no agreement has been reached yet by far, due to the limitation of different cutoff points and evaluation criteria [4-11, 15-17]. Particularly, there existed no unified and well-recognized cutoff points for $\mathrm{Nr}$ in gastric cancer. In this present study, we applied three cutoff points: $0,0.15,0.40$, produced by $\mathrm{X}$-tile, which demonstrated better discriminatory ability and more predictive accuracy than those proposed in previous studies, and found that patients with larger $\mathrm{Nr}$ were companied by worse biological behavior as well as more aggressive features than patients with smaller $\mathrm{Nr}$, both in the training and validation set.
Specifically, patients with larger $\mathrm{Nr}$ were found more frequently with the presence of advanced macroscopic type, poorly tumor differentiation, positive lymphovascular/ perineural invasion, larger tumor size and deeper tumor invasion as well as wider lymph nodes metastasis. Besides, logistic regression analysis in our study showed that tumor differentiation, lymphovascular invasion and $\mathrm{N}$ stage were independent risk factors for $\mathrm{Nr}$, suggesting that these three factors were closely associated with $\mathrm{Nr}$ and multicollinearity might exist between them. However, only $\mathrm{Nr}$ was confirmed to be positively correlated with $\mathrm{N}$ stage in spearman analysis, being consistent with previous studies $[11,14,18]$, which was the reason why we substituted $\mathrm{N}$ with $\mathrm{Nr}$ in the current TNM staging system to come up with a modified staging system, TNrM.

We also focused on the prognostic significance of Nr. Apart from age, tumor size, T stage and $\mathrm{N}$ stage, 
Table 5: Univariate and multivariate analyses of the patients' clinicopathologic factors by Cox regression model

\begin{tabular}{|c|c|c|c|c|}
\hline \multirow[t]{2}{*}{ Factors } & \multicolumn{2}{|c|}{ Univariate analysis } & \multicolumn{2}{|c|}{ Multivariate analysis } \\
\hline & HR $(95 \%$ CI $)$ & $P$ value & HR $(95 \%$ CI) & $P$ value \\
\hline Gender & $0.825(0.691-0.984)$ & 0.033 & $0.808(0.732-1.091)$ & 0.301 \\
\hline Age & $0.744(0.637-0.869)$ & $<0.001$ & $0.751(0.611-0.881)$ & $<0.001$ \\
\hline Tumor location & $0.933(0.852-1.022)$ & 0.138 & - & - \\
\hline Macroscopic type & $1.329(1.137-1.553)$ & $<0.001$ & $1.016(0.872-1.221)$ & 0.754 \\
\hline Tumor differentiation & $1.109(1.032-1.257)$ & 0.041 & $1.012(0.819-1.273)$ & 0.288 \\
\hline Lymphovascular invasion & $1.246(1.129-1.478)$ & $<0.001$ & $1.138(0.932-1.431)$ & 0.064 \\
\hline Perineural invasion & $1.051(1.002-1.171)$ & 0.087 & - & - \\
\hline Adjuvant chemotherapy & $1.244(1.112-1.653)$ & 0.032 & $1.104(0.912-1.412)$ & 0.136 \\
\hline Tumor size & $1.682(1.461-1.796)$ & $<0.001$ & $1.181(1.041-1.353)$ & 0.006 \\
\hline Retrieved lymph node & $0.893(0.652-1.012)$ & 0.211 & - & - \\
\hline T stage & $1.539(1.404-1.686)$ & $<0.001$ & $1.271(1.151-1.423)$ & $<0.001$ \\
\hline $\mathrm{N}$ stage & $1.593(1.473-1.723)$ & $<0.001$ & $1.209(1.013-1.389)$ & 0.003 \\
\hline Nr stage & $1.856(1.674-2.056)$ & $<0.001$ & $1.413(1.147-1.698)$ & $<0.001$ \\
\hline
\end{tabular}

HR: Hazard Ratio; CI: Confidence Interval; - :not enter the regression model.

A

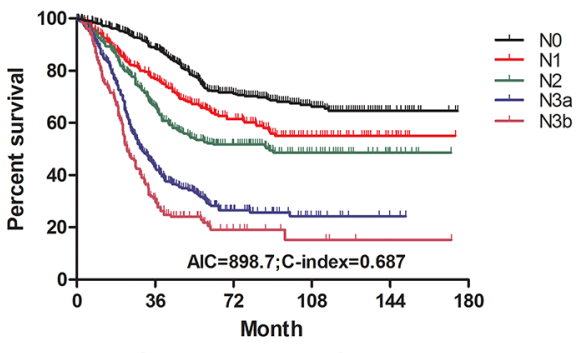

Survival analysis of $\mathrm{N}$ stage

C

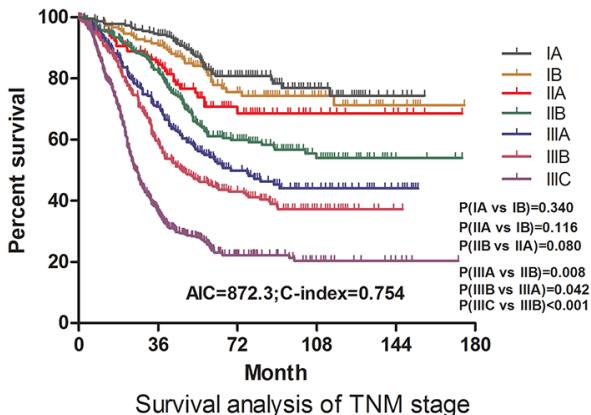

B

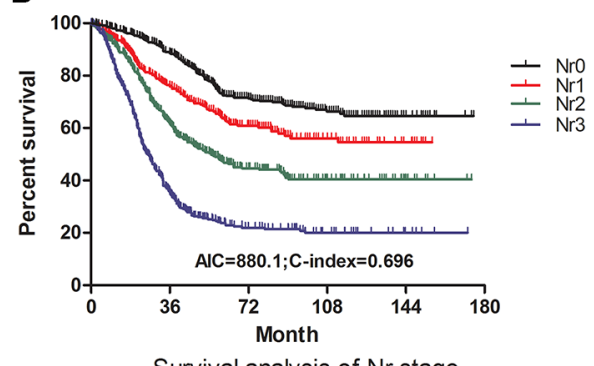

Survival analysis of $\mathrm{Nr}$ stage

D

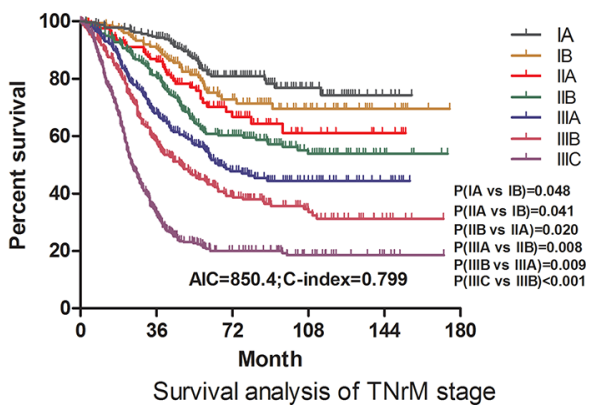

Figure 3: Comparative survival analysis on discriminatory ability and accuracy. (A), survival curves of patients according to subgroups of $\mathrm{N}$ stage. (B), survival curves of patients according to subgroups of $\mathrm{Nr}$ stage. (C), survival curves of patients according to subgroups of TNM stage. (D), survival curves of patients according to subgroups of TNrM stage. The significance of difference between survival curves was calculated by the log-rank test. 
Table 6: Comparison and validation of different cutoff points for $\mathrm{Nr}$

\begin{tabular}{|l|c|c|c|c|}
\hline \multicolumn{1}{c}{ Authors (ref.) } & Cutoff points & AIC & C-index & \multicolumn{1}{c|}{ P } \\
\hline Melis et al [5] & $0,0.30,0.60$ & 892.1 & 0.701 & $<0.05$ \\
\hline Deng et al [8] & $0,0.13,0.80$ & 900.3 & 0.698 & $<0.01$ \\
\hline Zeng et al [16] & $0,0.50,0.80$ & 912.4 & 0.674 & $<0.05$ \\
\hline Wang et al [10] & $0,0.067,0.30,0.70$ & 886.9 & 0.712 & $<0.05$ \\
\hline Lee et al [23] & $0,0.05,0.10,0.20,0.30$ & 998.8 & 0.675 & $<0.05$ \\
\hline Zhang et al [18] & $0,0.10,0.25$ & 1012.7 & 0.602 & $<0.01$ \\
\hline Wu et al [6] & $0,0.20,0.50$ & 862.5 & 0.772 & $<0.05$ \\
\hline Kutlu et al [9] & $0,0.20,0.50$ & 862.5 & 0.772 & $<0.05$ \\
\hline Zhou et al [11] & $0,0.20,0.50$ & 862.5 & 0.772 & $<0.05$ \\
\hline Wong et al [17] & $0,0.20,0.50$ & 862.5 & 0.772 & $<0.05$ \\
\hline
\end{tabular}

$\mathrm{Nr}$ stage was illustrated to be independent prognostic factors for gastric cancer patients in multivariate Cox regression analysis. Comparison analysis on survival prediction illustrated that $\mathrm{Nr}$ staging system had a better discriminatory prognostic ability and a more predictive

A

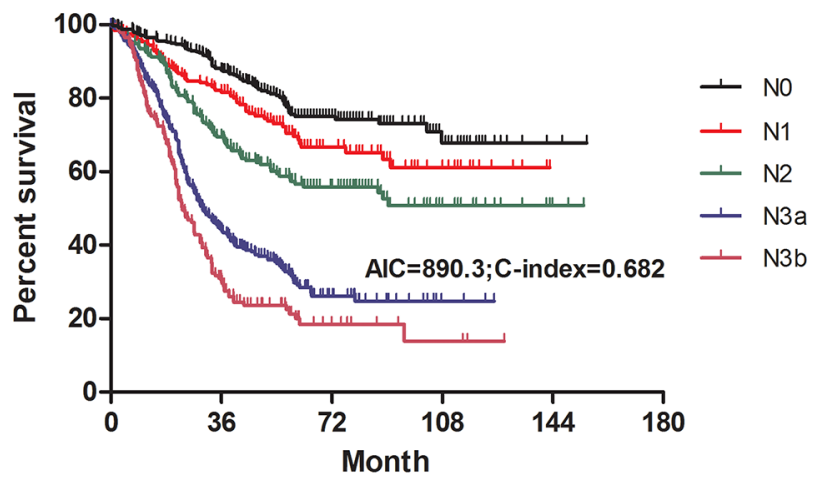

Survival analysis of $\mathrm{N}$ stage in patients with lymph nodes $\geq 15$

C

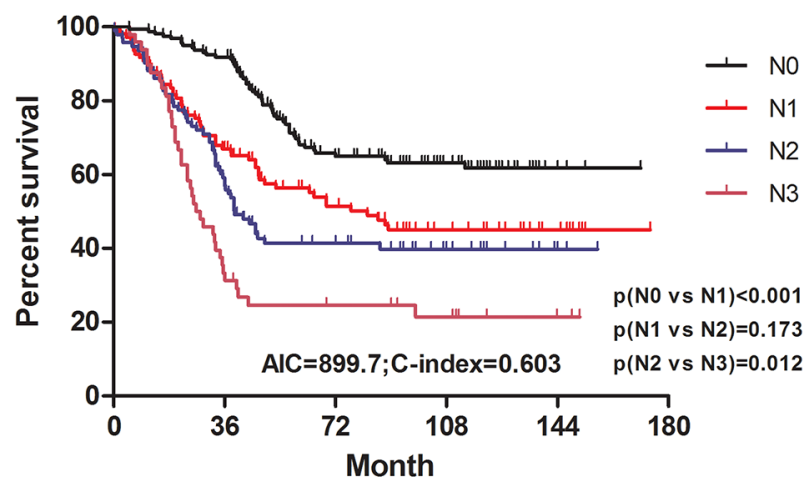

Survival analysis of $\mathrm{N}$ stage in patients with lymph nodes $<15$ accuracy than that of $\mathrm{N}$ staging system. Although our findings were consistent with the majority of studies [6-9], Espin et al concluded that, $\mathrm{Nr}$ stage showed no improvement in predictive accuracy than $\mathrm{N}$ stage, despite that $\mathrm{Nr}$ and $\mathrm{N}$ stage were both demonstrated to be

B

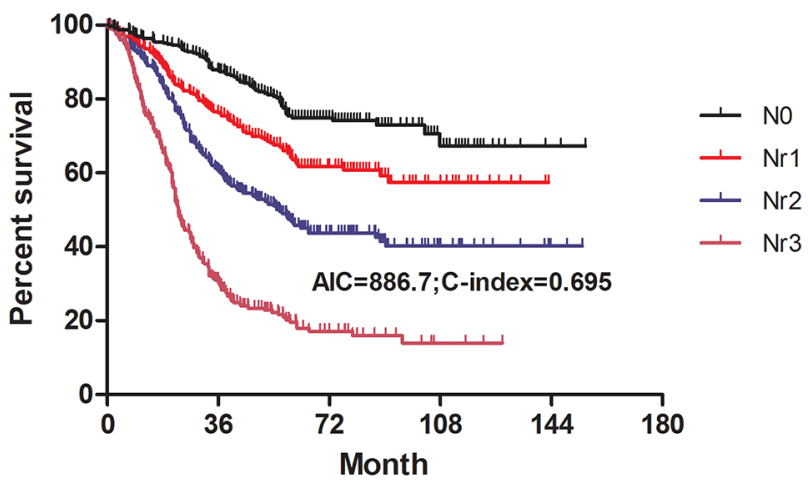

Survival analysis of $\mathrm{Nr}$ stage in patients with lymph nodes $\geq 15$

D

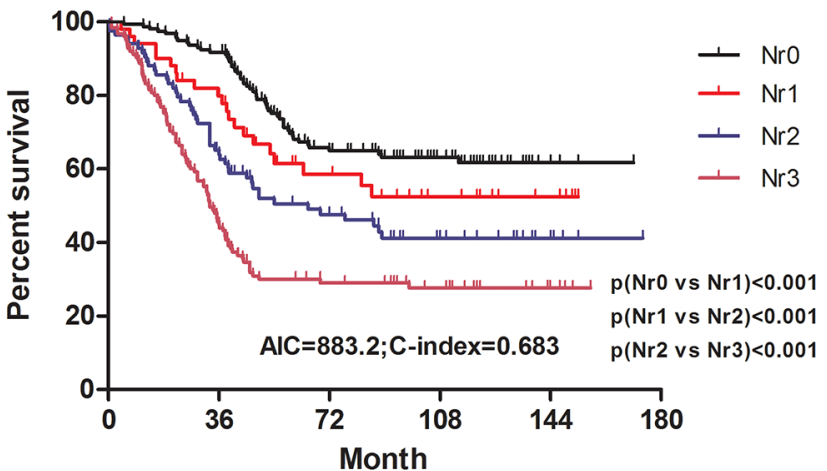

Survival analysis of $\mathrm{Nr}$ stage in patients with lymph nodes $<15$

Figure 4: Stratified comparative survival analysis on discriminatory ability and accuracy according to the different number of retrieved lymph nodes. (A, B): survival curves of patients with retrieved lymph node $\geq 15$ in terms of subgroups of $\mathrm{N}$ and $\mathrm{Nr}$ stage. (C, D): survival curves of patients with retrieved lymph node $<15$ in terms of subgroups of $\mathrm{N}$ and $\mathrm{Nr}$ stage. The significance of difference between survival curves was calculated by the log-rank test. 
independent prognostic factors [14], which was due to the consideration that the proportion of patients with retrieved lymph nodes $\geq 15$ in our study was not so much as that in Espin's study. Besides, nomogram, was also applied in our study to demonstrate the prognostic significance of independent factors on gastric cancer patients. Both in the training and validation set, the predictive accuracy of nomogram based on $\mathrm{Nr}$ was well demonstrated through calibration curves. But, we found that $\mathrm{Nr}$ but not $\mathrm{N}$ stage was included in the nomogram, which might due to the consideration that, $\mathrm{Nr}$ and $\mathrm{N}$ were both essential variables reflecting tumor biological features and interactive confounding effect like positive linear correlation existed between them. Moreover, taking the place of $\mathrm{N}$ stage in TNM staging system, $\mathrm{Nr}$ presented powerful survival discrimination for gastric cancer patients.

A good staging system, which is of great importance for gastric cancer patients in clinical practice, should be able to distinguish the survival difference among several subgroups of patients, and to provide accurate prognostic estimation and beneficial guidance of selecting appropriate adjuvant therapy [19]. As an powerful independent prognostic factor, the $\mathrm{N}$ stage in the current TNM staging system is based on the number of metastatic lymph nodes, regardless of the total number of retrieved lymph nodes in surgery. However, the prognosis of gastric cancer patients will be underestimated because of inappropriate staging in case of insufficient retrieved number of lymph nodes, especially when less than 15 lymph nodes are examined. The current TNM staging system was reported not to be an independent prognostic factor for the patients with retrieved lymph nodes fewer than 15 in a study from memorial sloan Kettering cancer Center [20]. Besides, the "stage migration" phenomenon could be observed in about $15 \%$ of patients with gastric cancer using the current TNM staging system [21]. Consequently, the prognostic value of $\mathrm{N}$ stage is questioned by many oncologists in light of these shortcomings mentioned above, and $\mathrm{Nr}$, defined as the ratio of the metastatic lymph node to the total number of retrieved lymph nodes, regardless of lymph nodes number, is considered as an alternative option. In this present study, $\mathrm{Nr}$ stage was shown to have better discriminatory ability and more accurately prediction than N. Although there was no predictive difference for patients with retrieved lymph nodes $\geq 15, \mathrm{Nr}$ stage revealed superiority in survival prediction for patients with retrieved lymph nodes $<15$, demonstrating that $\mathrm{Nr}$ stage would better compensate for $\mathrm{N}$ stage shortcomings in gastric cancer patients, which is consistent with previous studies [10, 22, 23]. Additionally, a modified staging system, TNrM staging system based on
A

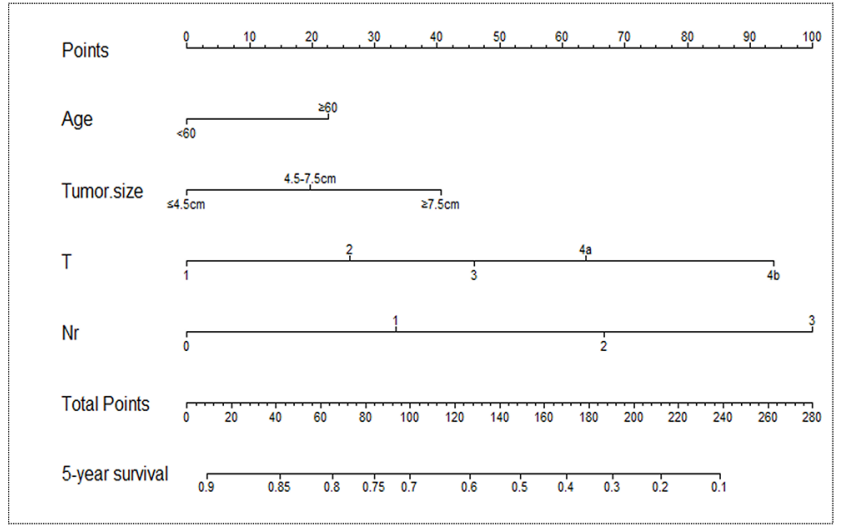

C

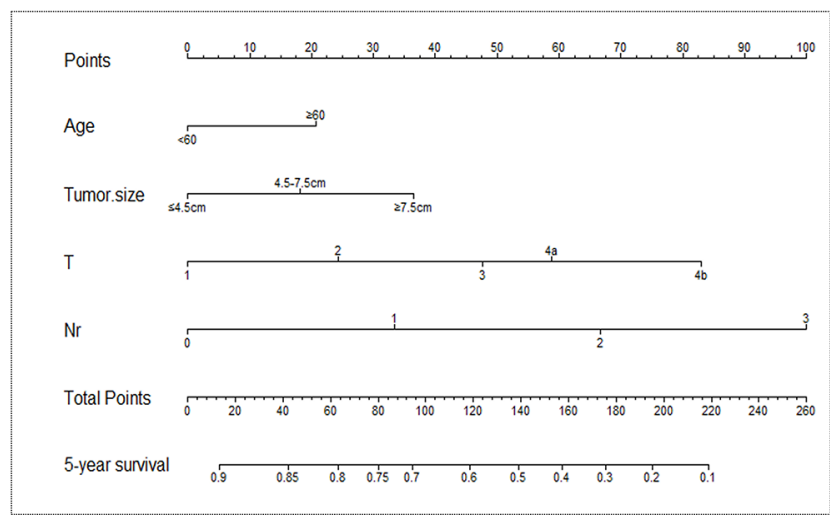

B

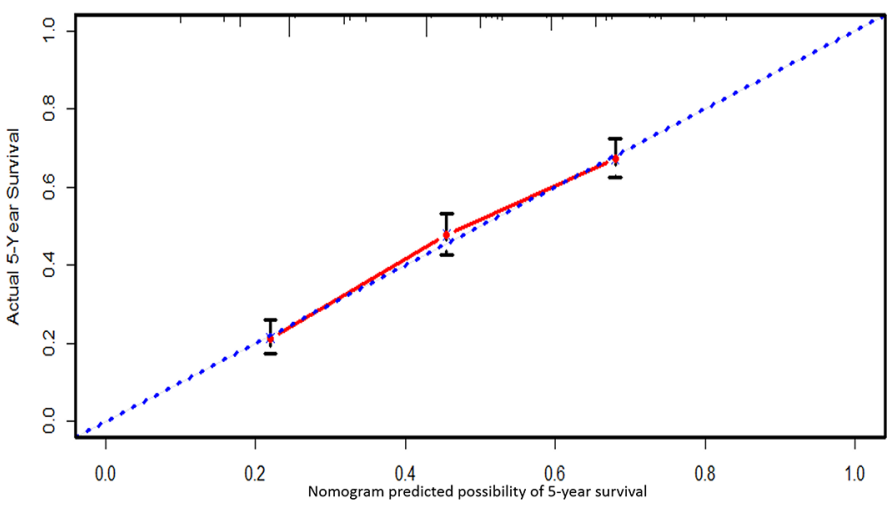

D

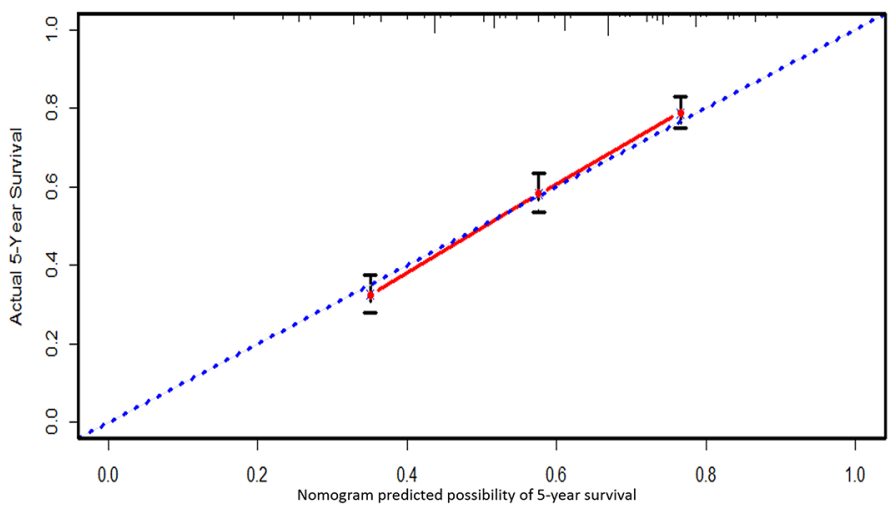

Figure 5: Nomogram plots and calibration curves based on $\mathrm{Nr}$ stage. (A, B): nomogram plots and calibration curves in the training set. (C, D): nomogram plots and calibration curves in the validation set. 
Nr stage, predicted more accurately on overall survival by comparison of the current TNM staging system according to the findings in our study (Figure 3), which was consistent with the findings mentioned in previous investigations [6, $11,16,17,24]$. To show the improvement we got in this study, we also validated the various cutoff points produced in previous studies, which was not commonly done by previous authors, and found that the $\mathrm{Nr}$ stage, categorized by our cutoff points: $0,0.15,0.40$ could produce the best prognostic discriminatory ability and predictive accuracy.

There were also some limitations in our study. First of all, our findings we got were just on the basis of a nonrandomized retrospective single-center study, which might be observed by chance in spite of the large sample. In addition, there might be various perioperative treatment of patients which could affect the survival and interfere the evaluation of the prognostic factors, especially the preoperative therapy may lead to the downstage of the gastric cancer and that is why these patients were excluded in this study. Therefore, multicenter investigations are needed to evaluate the TNrM staging system can whether be superior to TNM staging system for the GC patients before stronger statement can be done.

In conclusion, $\mathrm{Nr}$ could be considered as a reliable prognostic factor, even in patients with insufficient $(<15)$ retrieved lymph nodes, and TNrM staging system may improve the prognostic discriminatory ability and accuracy for gastric cancer patients undergoing radical gastrectomy, which should be superior to the current TNM staging system.

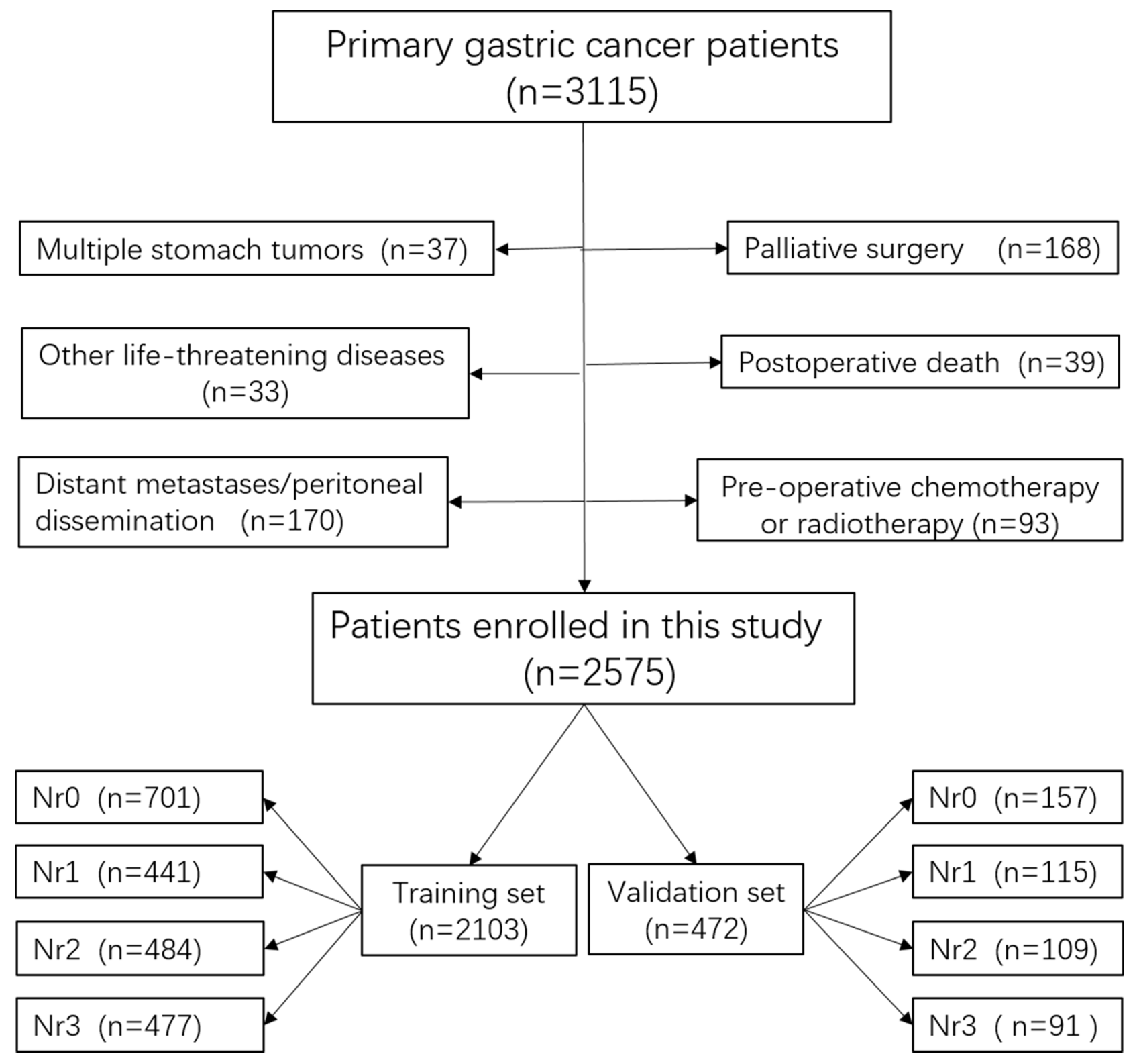

Figure 6: The flow chart of patients enrolled in this study. 


\section{MATERIALS AND METHODS}

\section{Patients}

The West China Hospital Research Ethics Committee approved the retrospective analysis of anonymous data. Patient records were anonymized and de-identified prior to analysis, and signed patient informed consent was waived because of the retrospective nature of the analysis.

A total of 3115 consecutive GC patients who received gastrectomy in West China Hospital from January 2000 to March 2011, were retrospectively evaluated in this study. The diagnosis of primary gastric cancer for all patients was confirmed by upper gastrointestinal endoscopy and biopsy. Patients were excluded on the condition that: (1) patients who underwent palliative surgery with positive residual margins; (2) with any preoperative chemotherapy or radiotherapy; (3) with multiple stomach tumors; (4) with another malignancy or any other life-threatening diseases diagnosed during three years prior to the operation; (5) with death due to postoperative complications in hospital; (6) with surgical findings of distant metastasis or peritoneal dissemination, or distant metastatic lymph nodes defined as M1 in JGCA [2] . Finally, 2575 patients were enrolled in this study as shown in Figure 6 and 2305 of these patients were followed up $(89.50 \%)$. Patients were randomly divided into two sets using X-tile with the ratio of 4.5:1, among which 2103 patients were used as the training set, whereas 472 patients were regarded as the validation set.

The clinicopathologic characteristics including of gender, age, tumor location, macroscopic type, tumor differentiation, lymphovascular invasion, perineural invasion, postoperative adjuvant chemotherapy, tumor size, number of retrieved lymph node, $\mathrm{T}$ stage, $\mathrm{N}$ stage, TNM stage evaluated according to $7^{\text {th }}$ edition of AJCC TNM staging system [3] and follow-up information were collected.

\section{Definition of Nr and TNrM staging system}

On the basis of cutoff points determined by X-tile, node ratio $(\mathrm{Nr})$, the ratio between the absolute number of metastatic lymph node and the total number of lymph nodes retrieved at the time of gastric resection, was divided into four groups: $\mathrm{Nr} 0(\mathrm{Nr}=0.0), \mathrm{Nr} 1(\mathrm{Nr}: 0.0$ $0.15), \mathrm{Nr} 2$ ( $\mathrm{Nr}: 0.15-0.40), \mathrm{Nr} 3(\mathrm{Nr} \geq 0.40)$, defined as $\mathrm{Nr}$ stage, corresponding to N0, N1, N2 and N3, respectively, in $\mathrm{N}$ stage. Therefore, we substituted $\mathrm{N}$ stage with $\mathrm{Nr}$ stage in TNM staging system, forming a new staging system, TNrM staging system, which was regarded as combination of T stage, Nr stage and M stage.

\section{Statistical analysis}

$\mathrm{X}$-tile program (Version 3.1.2, Yale University) was used to calculate the optimal cutoff points for $\mathrm{Nr}$ using minimum $P$ value from log-rank $\chi^{2}$ statistics, because that it does not only play a crucial role in complicated cutoff point selection but also can randomly divide a single cohort into training set and validation set [25]. Mann-Whitney U test in the SPSS version 19.0 was applied to evaluate ranked variables, while Chi-square test was performed to analyze unordered categorical variables. Logistic regression analysis was used to analyze risk factors for $\mathrm{Nr}$, whereas spearman correlation analysis was applied to evaluate the multicollinearity. Cox's proportional hazard regression model with conditional backward stepwise was displayed to univariate and multivariate survival analyses. The cumulative survival rates were calculated using the Kaplan-Meier method and life-table in the SPSS version 19.0, with subgroups compared by the log-rank test through GraphPad Prism 5. Nomogram and calibration curve were displayed using the package of Regression Modeling Strategies (URL http://CRAN.R-project.org/ package $=r m s$ ) in $\mathrm{R}$ (version3.1.2.URL http://www.Rproject.org/.) Comparisons between the different staging systems for the prognostic prediction were conducted with the package of Harrell Miscellanceous (URL http://CRAN.R-project.org/package=Hmisc.), in which Akaike information criterion (AIC) and concordance index (C-index) values within a cox proportional hazard regression model were calculated for each staging system to measure their discriminatory ability and accuracy, respectively. A smaller AIC value indicated a better model for predicting outcome [8], whereas a larger C-index demonstrated a more accurate prognostic prediction [26]. The two-sided $p$ value of less than 0.05 was considered to be statistically significant.

\section{ACKNOWLEDGMENTS}

All of the authors appreciate the grants from (1) National Natural Science Foundation of China (No. 81372344, No.81301867); (2) Sichuan Province Youth Science \& Technology Innovative Research Team, No.2015TD0009; (3) 1.3 .5 project for disciplines of excellence, West China Hospital, Sichuan University. We also thank the Volunteer Team of Gastric Cancer Surgery (VOLTGA), West China Hospital, Sichuan University, China, for the substantial work in data collection and follow-up of the database. Additionally, we appreciate Ms. Xue Zhao, a professor from the Institute of Foreign Language, Sichuan University, for her kind help in grammar revision and suggestion.

\section{CONFLICTS OF INTEREST}

The authors declare no potential conflicts of interest.

\section{FUNDING}

Domestic support from (1) National Natural Science Foundation of China (No. 81372344, No.81301867); (2) 
Sichuan Province Youth Science \& Technology Innovative Research Team, No.2015TD0009; (3) 1.3.5 project for disciplines of excellence, West China Hospital, Sichuan University

\section{REFERENCES}

1. Chen W, Zheng R, Baade PD, Zhang S, Zeng H, Bray F, Jemal A, Yu XQ, He J. Cancer statistics in China, 2015. CA Cancer J Clin. 2016; 66:115-32.

2. Japanese classification of gastric carcinoma: 3rd English edition. Gastric Cancer. 2011; 14:101-112.

3. Washington K. 7th edition of the AJCC cancer staging manual: stomach. Ann Surg Oncol. 2010; 17:3077-3079.

4. Saedi HS, Fanipakdel A, Shafaghi A, Ghorbani S. Evaluating the relation between patients-related factors and dissected lymph node ratio in gastric cancer. Indian $\mathrm{J}$ Cancer. 2015; 52:48-51.

5. Melis M, Masi A, Pinna A, Cohen S, Hatzaras I, Berman R, Pachter LH, Newman E. Does lymph node ratio affect prognosis in gastroesophageal cancer? Am J Surg. 2015; 210:443-450.

6. Wu XJ, Miao RL, Li ZY, Bu ZD, Zhang LH, Wu AW, Zong XL, Li SX, Shan F, Ji X, Ren H, Ji JF. Prognostic value of metastatic lymph node ratio as an additional tool to the TNM stage system in gastric cancer. Eur J Surg Oncol. 2015; 41:927-933.

7. Li X, Liu Y, Cao B, Liu B, Bai T, Li X, Mei L, Che X. Metastatic lymph node ratio and prognosis of gastric cancer at different pT stages. Hepatogastroenterology. 2015; 62:507-511.

8. Deng J, Zhang R, Wu L, Zhang L, Wang X, Liu Y, Hao X, Liang H. Superiority of the ratio between negative and positive lymph nodes for predicting the prognosis for patients with gastric cancer. Ann Surg Oncol. 2015; 22:1258-1266.

9. Kutlu OC, Watchell M, Dissanaike S. Metastatic lymph node ratio successfully predicts prognosis in western gastric cancer patients. Surg Oncol. 2015; 24:84-88.

10. Wang J, Dang P, Raut CP, Pandalai PK, Maduekwe UN, Rattner DW, Lauwers GY, Yoon SS. Comparison of a lymph node ratio-based staging system with the 7th AJCC system for gastric cancer: analysis of 18,043 patients from the SEER database. Ann Surg. 2012; 255:478-485.

11. Zhou Y, Zhang J, Cao S, Li Y. The evaluation of metastatic lymph node ratio staging system in gastric cancer. Gastric Cancer. 2013; 16:309-317.

12. Reim D, Loos M, Vogl F, Novotny A, Schuster T, Langer R, Becker K, Hofler H, Siveke J, Bassermann F, Friess H, Schuhmacher C. Prognostic implications of the seventh edition of the international union against cancer classification for patients with gastric cancer: the Western experience of patients treated in a single-center European institution. J Clin Oncol. 2013; 31:263-271.

13. Bilici A, Ustaalioglu BB, Gumus M, Seker M, Yilmaz B, Kefeli U, Yildirim E, Sonmez B, Salepci T, Kement M, Mayadagli A. Is metastatic lymph node ratio superior to the number of metastatic lymph nodes to assess outcome and survival of gastric cancer? Onkologie. 2010; 33:101-105.

14. Espin F, Bianchi A, Llorca S, Feliu J, Palomera E, Garcia O, Remon J, Sunol X. Metastatic lymph node ratio versus number of metastatic lymph nodes as a prognostic factor in gastric cancer. Eur J Surg Oncol. 2012; 38:497-502.

15. Unal D, Oguz A, Turak EE, Tasdemir A, Ozturk F, Kurtul N, Eroglu C. Ratio of metastatic to examined lymph nodes is a predictor of mortality in locally advanced gastric cancer treated chemo-radiotherapy. Hepatogastroenterology. 2014; 61:2141-2148.

16. Zeng WJ, Hu WQ, Wang LW, Yan SG, Li JD, Zhao HL, Peng CW, Yang GF, Li Y. Lymph node ratio is a better prognosticator than lymph node status for gastric cancer: A retrospective study of 138 cases. Oncol Lett. 2013; 6:1693-1700.

17. Wong J, Rahman S, Saeed N, Lin HY, Almhanna K, Shridhar R, Hoffe S, Meredith KL. Prognostic impact of lymph node retrieval and ratio in gastric cancer: a U.S. single center experience. J Gastrointest Surg. 2013; 17:2059-2066.

18. Zhang BY, Yuan J, Cui ZS, Li ZW, Li XH, Lu YY. Evaluation of the prognostic value of the metastatic lymph node ratio for gastric cancer. Am J Surg. 2014; 207:555-565.

19. Rice TW, Rusch VW, Ishwaran H, Blackstone EH. Cancer of the esophagus and esophagogastric junction: data-driven staging for the seventh edition of the American Joint Committee on Cancer/International Union Against Cancer Cancer Staging Manuals. Cancer. 2010; 116:3763-3773.

20. Dikken JL, van de Velde CJ, Gonen M, Verheij M, Brennan MF, Coit DG. The New American Joint Committee on Cancer/International Union Against Cancer staging system for adenocarcinoma of the stomach: increased complexity without clear improvement in predictive accuracy. Ann Surg Oncol. 2012; 19:2443-2451.

21. Bando E, Yonemura Y, Taniguchi K, Fushida S, Fujimura T, Miwa K. Outcome of ratio of lymph node metastasis in gastric carcinoma. Ann Surg Oncol. 2002; 9:775-784.

22. Kong SH, Lee HJ, Ahn HS, Kim JW, Kim WH, Lee KU, Yang HK. Stage migration effect on survival in gastric cancer surgery with extended lymphadenectomy: the reappraisal of positive lymph node ratio as a proper N-staging. Ann Surg. 2012; 255:50-58.

23. Lee SR, Kim HO, Son BH, Shin JH, Yoo CH. Prognostic significance of the metastatic lymph node ratio in patients with gastric cancer. World J Surg. 2012; 36:1096-1101. 
24. Lee YC, Yang PJ, Zhong Y, Clancy TE, Lin MT, Wang J. Lymph Node Ratio-based Staging System Outperforms the Seventh AJCC System for Gastric Cancer: Validation Analysis With National Taiwan University Hospital Cancer Registry. Am J Clin Oncol. 2014.

25. Camp RL, Dolled-Filhart M, Rimm DL. X-tile: a new bioinformatics tool for biomarker assessment and outcomebased cut-point optimization. Clin Cancer Res. 2004; 10:7252-7259.
26. Huitzil-Melendez FD, Capanu M, O’Reilly EM, Duffy A, Gansukh B, Saltz LL, Abou-Alfa GK. Advanced hepatocellular carcinoma: which staging systems best predict prognosis? J Clin Oncol. 2010; 28:2889-2895. doi: 2810.1200/JCO.2009.2825.9895. Epub 2010 May 2810. 